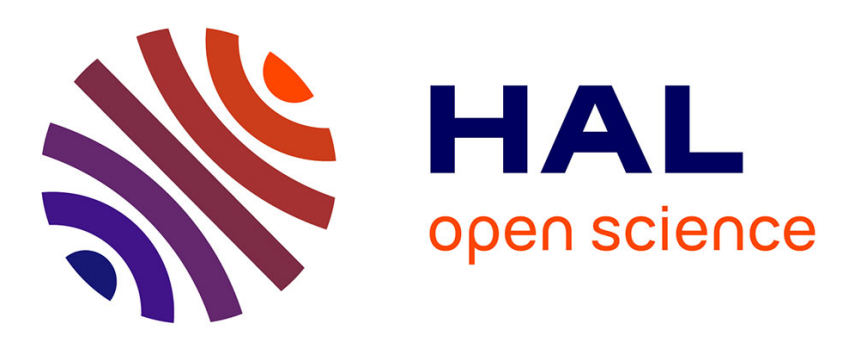

\title{
A New, Simple, "universal", Low Cost LED Driver and Controller
}

\author{
Akram Fayaz, Charif Karimi, Daniel Sadarnac
}

\section{To cite this version:}

Akram Fayaz, Charif Karimi, Daniel Sadarnac. A New, Simple, "universal", Low Cost LED Driver and Controller. 2012 IEEE Electrical Power and Energy Conference, Oct 2012, London, Canada. 6 p., 10.1109/EPEC.2012.6474969 . hal-00764788

\section{HAL Id: hal-00764788 \\ https://hal-centralesupelec.archives-ouvertes.fr/hal-00764788}

Submitted on 13 Dec 2012

HAL is a multi-disciplinary open access archive for the deposit and dissemination of scientific research documents, whether they are published or not. The documents may come from teaching and research institutions in France or abroad, or from public or private research centers.
L'archive ouverte pluridisciplinaire HAL, est destinée au dépôt et à la diffusion de documents scientifiques de niveau recherche, publiés ou non, émanant des établissements d'enseignement et de recherche français ou étrangers, des laboratoires publics ou privés. 


\section{A New, Simple, "universal", Low Cost LED Driver and Controller}

\author{
Akram M. Fayaz \\ Supélec \\ Department of Automation \\ Plateau de Moulon - 3 rue Joliot-Curie \\ 91192 Gif sur Yvette cedex - France \\ Email: Akram.Fayaz@supelec.fr
}

\author{
Charif Karimi and Daniel Sadarnac \\ Supélec \\ Department of Energy \\ Plateau de Moulon - 3 rue Joliot-Curie \\ 91192 Gif sur Yvette cedex - France \\ Email: charif.karimi@supelec.fr \\ Email:daniel.sadarnac@supelec.fr
}

\begin{abstract}
In this paper a new LED driver and its controller are conceived realized and experimentally validated. It presents several advantages compared with existing counterparts: First it uses a single converter while most of the existing drivers are based on a two-converter architecture. In the proposed approach the average current through the LED is directly regulated. The proposed driver is built around a "Sepic" converter because it allows lowering and raising of the battery voltage and, has the lowest number of components compered to "Inverter", "Zeta" or "flyback" necessitating an input filter to meet the required disturbance standards. Compared to "Cuk", with a sepic, constraints on the voltage across the capacitor in series are weaker and, the implementation of detection of current through the LED requires fewer components. Moreover, in the proposed architecture the two inductor of the sepic are coupled which along with a very fast current mode control of the internal loop, results to simpler transfer function. A PI controller is designed and its performance and robustness are experimentally verified for different converters.
\end{abstract}

\section{INTRODUCTION}

If natural light is one of the main ingredients of life, artificial light resulting from simple fire or more advanced components, has played a major role in the evolution of human beings and the progress of their societies. Today, beyond the elementary needs for lightning, this latter is alos becoming an important element of homes and cities decoration and an aspect of their image.

Today, in developed countries, the vast majority of lightning devices functions with electric energy. In 2010 the quantity of electricity needed to illuminate all French cities has been estimated about 1300 megawatts. In 2006, the annual cost of the public lighting of the Montaigne Avenue, in Paris, has been estimated about 65000 euros. The increasing cost and, the impact of electricity production on the environment and the human health has motived, the development of energyefficient devices and equipments. In the context of lightning, the first step towards energy economy was the substitution of incandescent bulbs by fluorescent (containing neon, argon, $\mathrm{CO} 2$, mercury, ...), halogen (containing brome, iodine, ...) or HID (containing mercury, sodium, xenon,... ) lamps. Most of these chemical elements are surely or potentially a threat to human health and to the environment. Some of them propagates electromagnetic field which is also considered to be hazardous for human health. Some of them produces infrared, ultraviolet or heat which causes deterioration of illuminated objects. They can also cause security problem in case of direct contact. The last but not the least, their electricity consumption, although lower than traditional bulbs is not always optimal. In this context, a discovery of 1962, by Nick Holonyak, is focusing again interest in recent years: LED or Light Emitting Diode. Unlike the first generation LEDs, the new ones have performances that allow them to be used in indoor and outdoor lighting applications with real assets:

- Energy savings can be very high depending on the lamps replaced.

- LED does not harm environment or health as there are no elements such as mercury. LED produces no infrared or ultraviolet or heat and so causes no deterioration of illuminated objects or security problem in case of direct contact.

- LEDs are low voltage supply, which may be important in sensitive or electrical safety is paramount and it is therefore very suitable for battery operation or solar panel.

- The LED does not fear the cold and has no warm up time and has its full capacity when the power turns on. It has a very fast response times allowing effects like flash, strobe, dimming, ...

- LED has a small size which makes it very suitable for small footprint applications.

- LEDs can have a lifespan of 50,000 hours which is 13 years with use of 12 hours per day or 25 years for use of 5 hours per day. However this lifetime depends on the type of LED, its implementation and design of the lamp or fixture associated.

- LED lighting offers a multitude of possibility for creative designs and illuminating.

To get the full benefit of the above mentioned advantages, the supplying circuit and its control has a crucial role. The luminous intensity of a LED is adjustable by the current which is injected to it. Conventionally, the power to the LED is supplied by a two-stage power converter: The first stage is a DC/DC converter with high switching frequency providing 
a current equal to the nominal current of the LED. The stage second is another converter that chaps the current provided by the first stage at a frequency of the order of kilohertz and feeds the LED.

We believe that this strategy and the corresponding current control structure have the following have at least the following drawbacks:

- The structure is complex and the number of components is high.

- The LED is not used in optimal conditions in the sense that the chapping of the current through the LED, even to a few $\mathrm{kHz}$, can affect its life-time.

To overcome the above mentioned problems, in this paper we propose first a one-converter structure to replace the twostage (two-convert) architecture, and then regulate the average current directly.

\section{Choice OF The ARChitecture}

To use the same converter regardless of the desired voltage level at the terminals of LEDs, we propose to study converters that can lower and raise the battery voltage. This constraint eliminates the use of the traditionally used Buck [9] or Boost [5], [7], [3] converters. Also, in the chosen category, structure as "Zeta", "flyback" [8], [2] or "buck-boost" [10], [7], [4] use a large number of components because we must add to the structure an input filter to meet the required disturbance standards. Thus, it remains essentially the "Cuk" [1] and "Sepic" structures. The Sepic seems advantageous for the following reasons:

- Constraints on the voltage across the capacitor in series are weaker.

- As the output voltage is not reversed, the implementation of detection of current through the LED (for control purposes) requires fewer components.

- The transfer function, especially in current mode, is simpler.

Therefore, to regulate the average current in the LED, we propose the implementation of the structure Sepic. Moreover, in the our Sepic based architecture, the inductors are coupled. Many papers, in power electronics literature , underline various benefits of coupling inductors (see for example: [11], [12], [13], [14]).

\section{SEPIC OPERATING IN CONTINUOUS CONDUCTION}

To reduce the volume of passive elements, a "high enough" switching frequency (around $200 \mathrm{kHz}$ ) is used and, the converter is built by coupling the two inductors $L_{1}$ and $L_{2}$. We will see later that the coupling of the two inductors simplifies the transfer function of the converter and thus the controller design.

The magnetizing current, $I_{m}$, in the coupled inductors is the sum of currents $I_{e}$ and $I_{2}$. It is also the current through the transistor during its conduction. In the proposed approach, to regulate the average current in the current mode, the reference current is the magnetizing current.

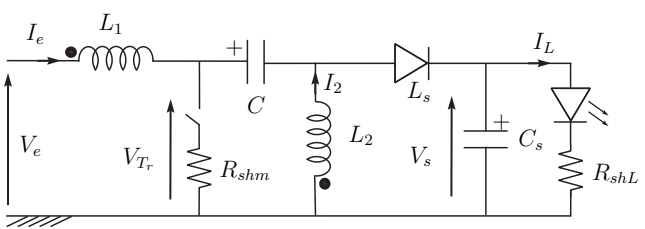

Fig. 1. Sepic converter with coupled inductors.

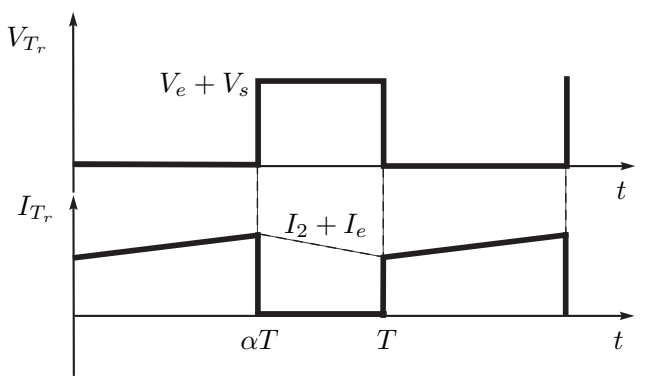

Fig. 2. Voltage and current through the transistor.

\section{Modeling}

\section{A. Average model of the converter}

To build the average model of the converter, the following simplifying assumptions are made:

- The input voltage $V_{e}$ is considered constant (very slowly varying).

- The two inductors $L_{1}$ and $L_{2}$ are fully coupled. This implies $V_{C}=V_{e}$ and according to the first assumption considered constant. This will result to a model of lower order compared to the case without inductors' coupling.

- First the variations of the ripple of the magnetizing current is neglected which results to a first order model with one unstable zero. Then another model is built by taking into account the ripples which results to a second order model with one unstable zero.

- The variation of the compensation current is neglected. It is assumed that the LED is equivalent to a constant voltage source in series with a resistance: $V_{0}+R_{L} I_{L}$, where $R_{L}$ refers to the sum of LED's internal resistance and the shunt resistance $R_{s h L}$.

With the simplifying assumptions above, the Sepic converter can be represented by the following averaged model circuit:

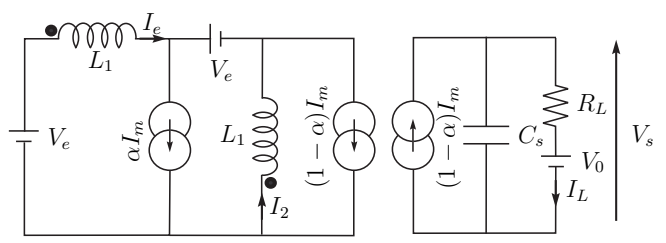

Fig. 3. Equivalent average circuit of the sepic when inductors are coupled.

It is also possible to present the converter by the following scheme: 


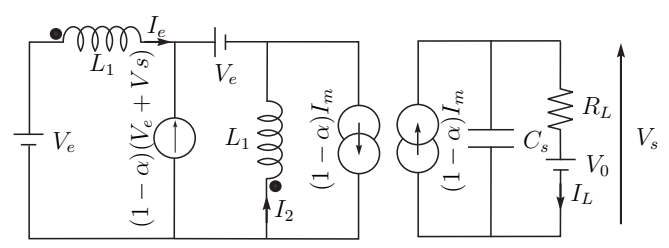

Fig. 4. Equivalent average circuit of the sepic when inductors are coupled.

From the above figures particularly Figure 4, we deduce the model of the system as follows.

\section{B. Transfer function}

The goal is to regulate the current in the LED while imposing a fast inner loop. The latter is achieved using the current mode control, adapted to the magnetizing current $I_{m}=I_{e}+I_{2}$. Referring us to Figure 4, and using Kirchhoff laws, we can write the following equations

$$
\begin{aligned}
& \left\{\begin{array}{l}
(1-D) I_{m}=C \frac{d V_{s}}{d t}+I_{L} \\
V_{e}-(1-D)\left(V_{e}+V_{s}\right)=L_{m} \frac{d I_{m}}{d t} \\
V_{S}=V_{0}+R_{L} I_{L}
\end{array}\right. \\
& \Rightarrow\left\{\begin{array}{l}
(1-D) I_{m}=R_{L} C_{s} \frac{d I_{L}}{d t}+I_{L} \\
D V_{e}-(1-D)\left(V_{0}+R_{L} I_{L}\right)=L_{m} \frac{d I_{m}}{d t}
\end{array}\right.
\end{aligned}
$$

where $D$ represents the duty ratio and $L_{m}=L_{1}=L_{2}$ is the magnetizing inductor. The other variables and parameters are defined above or in Figures 1, 3 and 4. For small variations around the operating point $\left(I_{L 0}, I_{m 0}, \alpha_{0}, V_{e 0}, V_{s 0}, I_{0}\right)$ the variation of the involved variables in the above equations can be written as

$$
\begin{aligned}
& I_{L}=I_{L 0}+i_{L}, I_{m}=I_{m 0}+i_{m}, V_{e}=V_{e 0} \\
& D=\alpha_{0}+\alpha, V_{s}=V_{s 0}+R_{L}\left(I_{0}+i_{L}\right)
\end{aligned}
$$

Inserting theses expressions into the equations (1) we obtain

$$
\left\{\begin{array}{r}
\left(1-\alpha_{0}-\alpha\right)\left(I_{m 0}+i_{m}\right)=R_{L} C_{s} \frac{d i_{L}}{d t}+I_{L 0}+i_{L} \\
\left.\left(\alpha_{0}+\alpha\right) V_{e}-\left(1-\alpha_{0}-\alpha\right)\left(V_{0}+R_{L} I_{L 0}+R_{L} i_{L}\right)\right) \\
=L_{m} \frac{d i_{m}}{d t}
\end{array}\right.
$$

In steady-state, i.e., when $i_{L}=i_{m}=\alpha=i_{L}=\frac{d i_{L}}{d t}=\frac{d i_{m}}{d t}=$ 0 , equations (2) give

$$
\left\{\begin{array}{l}
I_{m 0}\left(1-\alpha_{0}\right)=I_{L 0} \\
\frac{\alpha_{0}}{1-\alpha_{0}} V_{e}=V_{0}+R_{L} I_{L 0}
\end{array}\right.
$$

Neglecting second order (nonlinear) terms in equations (2) and tacking their Laplace transform, they become

$$
\left\{\begin{array}{l}
\left(1-\alpha_{0}\right) i_{m}-\alpha I_{m 0}=R_{L} C_{s} s i_{L}+i_{L} \\
\alpha\left(V_{e}+V_{0}+R_{L} I_{L 0}\right)-\left(1-\alpha_{0}\right) R_{L} i_{L}=L_{m} s i_{m}
\end{array}\right.
$$

By eliminating $\alpha$ between the two equations of (4) and using (3), we obtain the following transfer function between the output current $i_{L}$ (current in the LED) and the reference current, $i_{m}$ :

$$
H(s)=\frac{i_{m}}{i_{L}}=G \frac{1-\tau_{n} s}{1+\tau_{d} s}
$$

where $G, \tau_{n}$ and $\tau_{d}$ are given by

$$
\begin{aligned}
G & =\frac{\left(1-\alpha_{0}\right)}{1+\frac{\left(1-\alpha_{0}\right)^{2} R_{L} I_{m 0}}{V_{e}}}, \tau_{n}=\frac{L_{m} I_{m 0}}{V_{e}}, \\
\tau_{d} & =\frac{R_{L} C_{S}}{1+\frac{\left(1-\alpha_{0}\right)^{2} R_{L} I_{m 0}}{V_{e}}}
\end{aligned}
$$

One observes that the transfer function admits an unstable zero. Generally the model obtained for this converter is of higher order [15], [16]. In [16], a transfer function from the duty ratio to the output voltage and, without inductors' coupling is built which admits four poles and three unstable zeros.

\section{Numerical values}

Here the values of $G, \tau_{n}$ and $\tau_{d}$ are computed for $V_{e}=$ $12 \mathrm{~V}, V_{0}=18 \mathrm{~V}, R=1, I_{L 0}=1 \mathrm{~A}\left(\alpha_{0}=0.6\right), C_{s}=10 \mu \mathrm{F}$ and $L_{m}=50 \mu \mathrm{H}$. It results to $G=0.454, \tau_{n}=5.4 \times 10^{-6}$ and $\tau_{d}$. The resulting tranfer function is

$$
H(s)=0.454 \frac{1-5.4 \times 10^{-6} s}{1+31 \times 10^{-6} s}
$$

The bode diagram of (7) is given in Figure 5 by dashed lines.

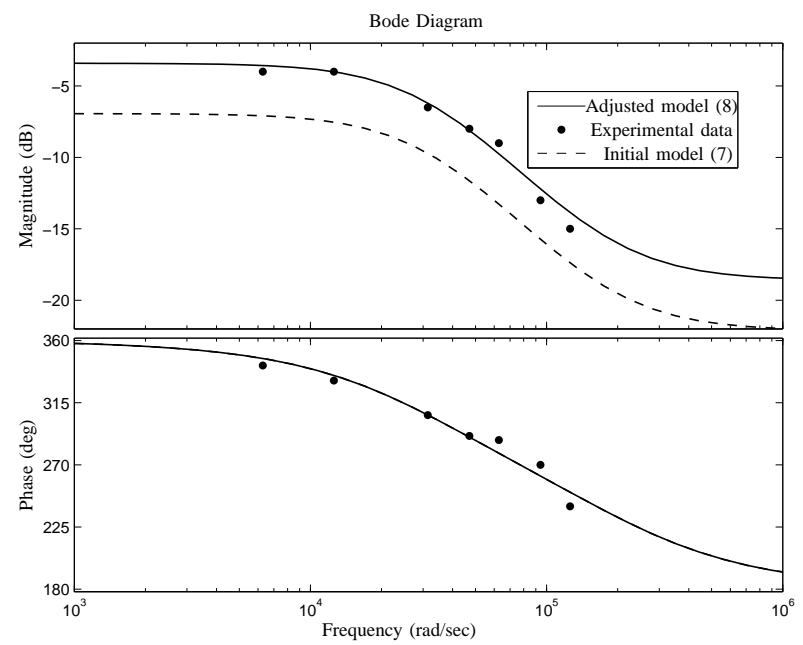

Fig. 5. Bode diagrams of the initial and the adjusted transfer functions

\section{Adjustment of the model}

To evaluate the quality of this model, its bode diagram is compared with experimental measures given by the table

\begin{tabular}{|l||l|l|l|l|}
\hline frquency $(\mathrm{kHz})$ & 1 & 2 & 5 & 7.5 \\
\hline \hline frquency $(\mathrm{k} \mathrm{rad} / \mathrm{sec})$ & 6.28 & 12.57 & 31.41 & 47.12 \\
\hline Magnitude $(\mathrm{dB})$ & -4 & -4 & -6.5 & -8 \\
\hline phase $($ degree $)$ & -18 & -29 & -54 & -69 \\
\hline
\end{tabular}

\begin{tabular}{|l||l|l|l|}
\hline frquency $(\mathrm{Hz})$ & 10 & 15 & 20 \\
\hline \hline frquency $(\mathrm{k} \mathrm{rad} / \mathrm{sec})$ & 62.83 & 94.25 & 125.66 \\
\hline Magnitude $(\mathrm{dB})$ & -9 & -13 & -15 \\
\hline phase (degree) & -72 & 90 & -120 \\
\hline
\end{tabular}


The experimental data in Figure 5, shows mainly a gap of approximately $3.5 \mathrm{~dB}$ between the static gain of the transfer function (7) and the one of the process. To compensate this gap the transfer function is multiplied by 1.5 giving

$$
H(s)=0.68 \frac{1-5.4 \times 10^{-6} s}{1+31 \times 10^{-6} s}
$$

The bode diagram of (8) is given in Figure 5 by solid lines. It shows that this latter transfer function matches well the experimental data and thus will be used to compute the controller.

Remark In the above computation of the transfer function, the variation of the magnetizing current ripple has been neglected. Here below, a new transfer function is computed by tacking them into account. This results in a second order transfer function.

\section{E. Transfer function taking into account the variations of current ripple}

Here the cumbersome details of the computations are dropped and only the final result is given. We would be pleased to provide them to interested readers. If for the reference current, the ripple of $I_{m}$ is taken into account and it is written as $I_{r e f}=I_{m}-\frac{\Delta I m}{2}$, the transfert function becomes

$$
\frac{i_{L}}{i_{r e f}}=H(s)=G \frac{1-N_{1} s}{1+D_{1} s+D_{2} s^{2}}
$$

with

$$
\begin{gathered}
G=\frac{1}{\left[\frac{1}{1-\alpha_{0}}+\left(1-\alpha_{0}\right) R_{L}\left(\frac{I_{m 0}}{V e}+\left(1-2 \alpha_{0}\right) \frac{1}{2 L_{m} f}\right)\right]} \\
N_{1}=\left[\frac{I_{m 0}}{V_{e}}-\frac{\alpha_{0}}{L_{s} 2 f}\right] L_{m} \\
D_{1}=G\left[\frac{1}{2 f}+\frac{1}{1-\alpha_{0}} R_{L} C_{s}\right] \\
D_{2}=G \frac{R_{L} C_{s}}{2 f}
\end{gathered}
$$

The only new parameter appearing here is $f$ which designates the switching frequency. The transfer function is now of second order but still has just one unstable zero. Numerical computations show that at "low frequency" (up to $20 \mathrm{kHz}$ ) the behaviors (9) and (5) are almost identical.

\section{CONTROLler Design}

\section{A. Choice of the controller architecture}

The controller choice was mainly guided by the following considerations: Simplicity in the sense that the controller should admit the lowest possible number of tunable parameter. This also involves that the lowest number of electric components will used (lower cost). The second major requirement is robustness with respect to LED's parameters' variations. This makes the controller "universal", in the sense that it works for a large class of LEDs with suitable performances. And finally, in steady state, the "precise required current" must be provided to the LED. This means that the regulated system should not admit steady-state error. According to these considerations a PI controller has been chosen. Both simulations and experimental results show that the required performances are largely achieved.

\section{B. Computation of the contyroller parameters}

In this paper the parameters of the controller are computed by pole placement. The closed loop transfer function of (5) in series with a PI controller, $k_{p i}\left(1+1 / \tau_{i} s\right)$, is given by

$$
\begin{gathered}
\frac{k_{p i} G\left(1-\tau_{n} s\right)\left(1+\tau_{i} s\right)}{\left(\tau_{i} \tau_{d}-k_{p i} \tau_{n} \tau_{i}\right) s^{2}+\left(\tau_{i}+k_{p i} \tau_{i}-k_{p i} \tau_{n}\right) s+k_{p i}} \\
=\frac{\frac{k_{p i} G\left(1-\tau_{n} s\right)\left(1+\tau_{i} s\right)}{\left(\tau_{i} \tau_{d}-k_{p i} \tau_{n} \tau_{i}\right)}}{s^{2}+\frac{\tau_{i}+k_{p i} \tau_{i}-k_{p i} \tau_{n}}{\tau_{i} \tau_{d}-k_{p i} \tau_{n} \tau_{i}} s+\frac{k_{p i}}{\tau_{i} \tau_{d}-k_{p i} \tau_{n} \tau_{i}}}
\end{gathered}
$$

As the denominator of (10) is a second order polynomial, it is clear that the pole of the closed loop system can be placed anywhere on the complex plan by appropriate choice of the two parameters of the PI controller. However, a well known criterion for robustness is that the closed loop shouldn't be much faster, or equivalently, the bandwidth of the closed loop shouldn't be much larger than the one of the system when an unstable zero is located near by. To respect this criterion, the first overshoot and the time of the first overshoot have been chosen accordingly: $\left(t_{1}, D_{1}\right)=\left(2 \times 10^{-4}\right.$ sec, $\left.2 \%\right)$. These result to the following values for the damping coefficient and the natural frequency of the closed loop: $\zeta=0.78$ and $\omega_{n}=25101 \mathrm{rad} / \mathrm{sec}$. According to these values, the poles of the closed loop is given by the roots of the polynomial

$$
s^{2}+39158 s+6.3006 \times 10^{8}
$$

Identifying (11) with the denominator of (10), the following equations are obtained.

$$
\begin{aligned}
& \frac{\tau_{i}+k_{p i} \tau_{i}-k_{p i} \tau_{n}}{\tau_{i} \tau_{d}-k_{p i} \tau_{n} \tau_{i}}=39158 \\
& \frac{k_{p i}}{\tau_{i} \tau_{d}-k_{p i} \tau_{n} \tau_{i}}=6.3006 \times 10^{8}
\end{aligned}
$$

With $\tau_{d}=31 \times 10^{-6} \mathrm{sec}$ and $\tau_{n}=5.4 \times 10^{-6} \mathrm{sec}$, these equations give $k_{p i} \simeq 0.38$ and $\tau_{i} \simeq 1.4 \times 10^{-5}$ sec. Figure 6 shows that the closed loop response achieves the specified requirements.

\section{Robustness}

To verify the robustness of the controller with respect to parameters variations, $G, \tau_{d}$ and $\tau_{n}$ have been modified by $500 \%$ (one parameter a time), while the controller is kept unchanged (Figures 7 and 8). In Figure 9 all three parameters are modified by $300 \%$ at the same time. The results show that the stability of the closed loop is maintained as well as zero steady-state error. The response time is longer and transient is deteriorated particularly when parameters' values are increased simultaneously, however stability is maintained and there is no error in steady state. 


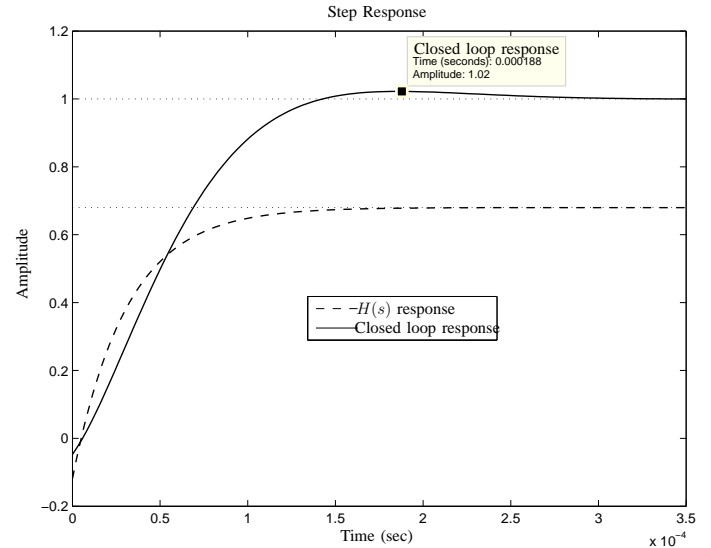

Fig. 6. Closed loop response satisfying the specified requirements
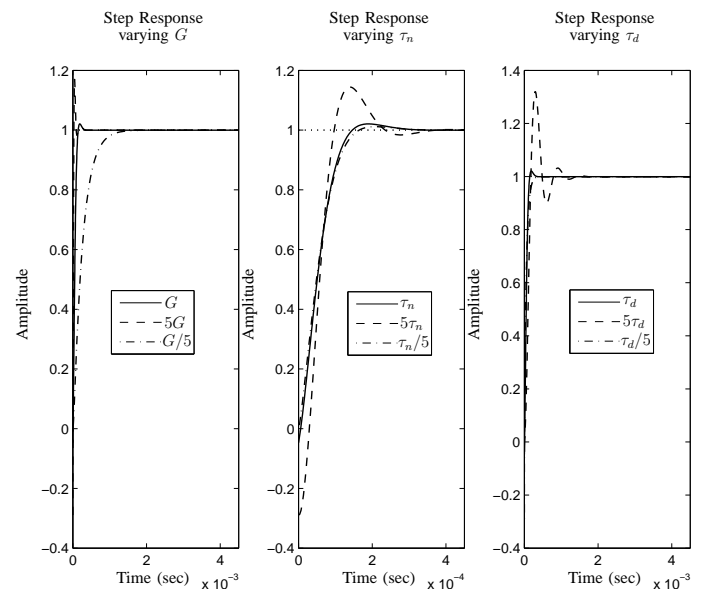

Fig. 7. Parameters individually modified by $500 \%$.

\section{Simulation with LTSpice and experimental results}

Simulations are realized with the LTSpice circuit of the Figure 10 and the real tests with the test bed of the Figure 11. The first simulation and real test have been realized using the LED for which the transfer function and then the controller have been computed $\left(V_{0}=18 V, R_{L}=1 \Omega\right)$. The results are given in Figures 12 and 13. Both simulation and real experiment provide very good results. With the same controller, simulation and real test have been performed with another LED $\left(V_{0}=11 V, R_{L}=3 \Omega\right)$. The results are given in Figures 14 and 15.

Despite large differences between the parameters of the two LED, the performances of the regulated system are still very satisfactory.

\section{LUMINOUS EFFICIENCY WITH RESPECT TO CURRENT (SPECTRUM)}

The luminous efficiency of a LED depends on three parameters: the color, the supply current and the operating temperature. The color is intrinsic to the LED and depends on its composition. The other two parameters, i.e., the supply current and the operating temperature are related to the integration of the LED into the circuit. For this work we have measured
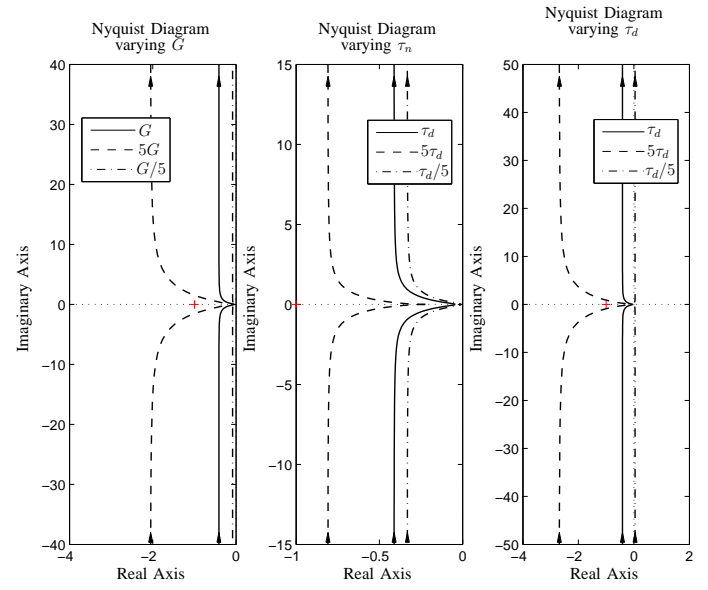

Fig. 8. Parameters individually modified by $500 \%$.
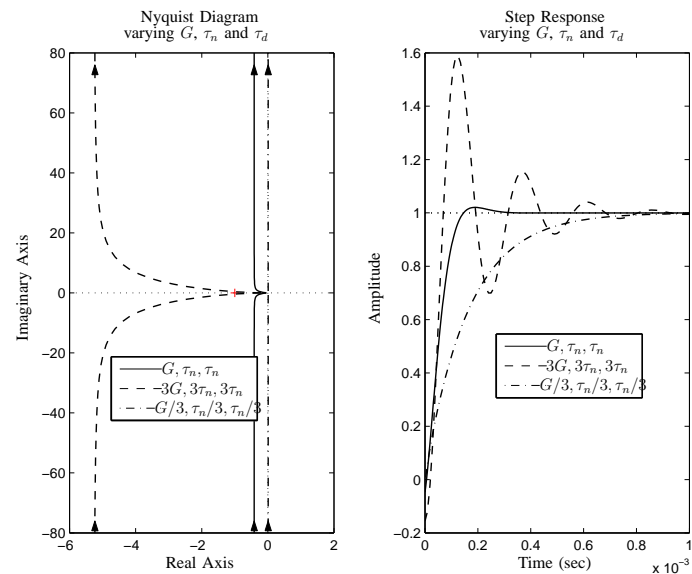

Fig. 9. All three parameters simultaneously modified by $300 \%$.

the light spectrum for different values of the current in the LED and for a non-chopped current we obtain the following values: For the maximum current $(0.8 A)$, two spectrum lines at $454 \mathrm{~nm}$ (blue) and $456 \mathrm{~nm}$ (green/yellow). For a low current value $(0.3 A)$, we obtain again two spectrum lines at $456 \mathrm{~nm}$ (blue) and $456 \mathrm{~nm}$

\section{CONCLUSION}

The above work has first shown that the commonly used two converters based architecture can successfully be replaced by a unique converter and the current through the LED can be directly regulated. The combination of an extremely fast current mode control and the coupling of the two inductors in the Sepic, provide much simpler models. Taking benefit of model simplicity a robust PI controller has been designed showing very good performances both in simulation with LTspice and real experiment on a laboratory prototype.

\section{REFERENCES}

[1] de Britto J.R, Demian A.E., de Freitas L.C., Farias V.J., Coelho E.A.A., Vieira J.B., A proposal of Led Lamp Driver for universal input using Cuk converter, IEEE Power Electronics Specialists Conference, PESC (Print ISBN: 978-1-4244-1667-7 ), Rhodes Island, pp. 2640 - 2644, 2008. 


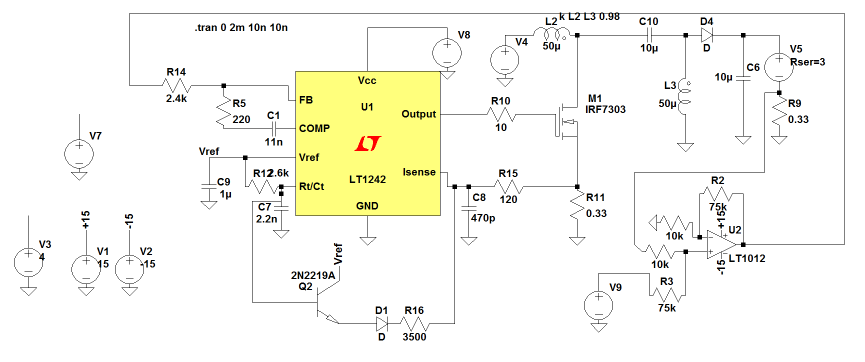

Fig. 10. Circuit corresponding to the converter and the controller realized with LTSpice ${ }^{\mathrm{TM}}$.
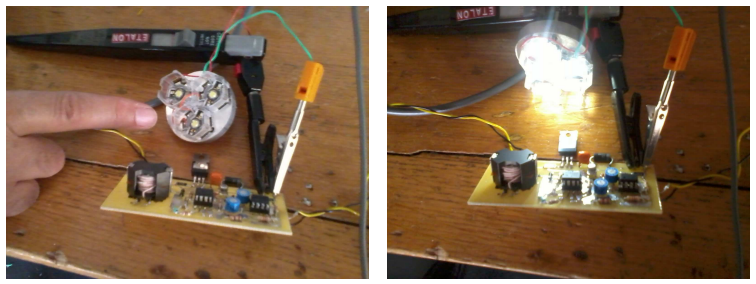

Fig. 11. Pictures of the test bed

[2] Cheng Y.K., Cheng K.W.E., General Study for using LED to replace traditional lighting devices, Power Electronics Systems and Applications Conference, IPCSA (Print ISBN: 962-367-544-5), Hong Kong, pp. 173 177, 2006.

[3] Doshi Montu, Zane Regan, Digital Architecture for Driving Large LED Arrays with Dynamic Bus Voltage Regulation and Phase Shifted PWM, Applied Power Electronics Conference, APEC (Print ISBN: 1-4244-07133), Anaheim - CA, pp. 287 - 293, 2007.

[4] Chen C.C., Wu C.-Y., Wu T.-F., LED back-light driving system for LCD panels, IEEE Twenty-First Annual Conference and Expositions on Applied Power Electronics, APEC (Print ISBN: 0-7803-9547-6), 2006.

[5] Xiaoru Xu, Xiaobo Wu High dimming ratio LED driver with fast transient boost converter, IEEE Power Electronics Specialists Conference, PESC (Print ISBN: 978-1-4244-1667-7), Rhodes Island, pp. 4192 - 4195, 2008.

[6] van der Broeck Heinz, Sauerlander Georg, Wendt, Matthias, Power driver topologies and control schemes for LEDs, IEEE Twenty-second Annual Conference on Applied Power Electronics, APEC (Print ISBN: 1-42440713-3), Anaheim - CA, pp. 1319 - 1325, 2007.

[7] Philip Drake, High-Brightness LED Control Interface MCU-Based LED Drivers Using DC-to-DC Converters: Buck, Boost, and Buck-Boost, Freescale Semiconductor Application Note, Document Number: AN3321, 2007.

[8] Huang-Jen Chiu, Hsiu-Ming Huang, Hong-Tzer Yang, Shih-Jen Cheng, An improved single-stage Flyback PFC converter for high-luminance lighting LED lamps, International Journal of Circuit Theory and Applications, Wiley InterScience, vol. 36, pp. 205 - 210, 2008.

[9] Peter Green, Simple, Efficient, High-Brightness-LED Control, Bodo's Power Systems, 2007.

[10] Yuequan Hu, Jovanovic M.M., LED Driver With Self-Adaptive Drive Voltage, IEEE Transactions on Power Electronics, Volume 23, Issue 6, pp. $3116-3125,2008$.

[11] Robert Balog, Philip T. Krein and David C. Hamill, Coupeled inductors - A basic building bloc, [Online]. Available: http://www.hamill.co.uk/pdfs/ciabfbb_.pdf

[12] Jieli Li, Charles R. Sullivan, Aaron Schultz, Coupled-Inductor Design Optimization for Fast-Response, IEEE Applied Power Electronics Conference, Volume: 2, vol. 2, pp. 817 - 823, 2002.

[13] Jeff Falin, Coupled inductors broaden dc dc converter usage, [Online]. Available: http://www.ti.com/lit/an/slyt380/slyt380.pdf

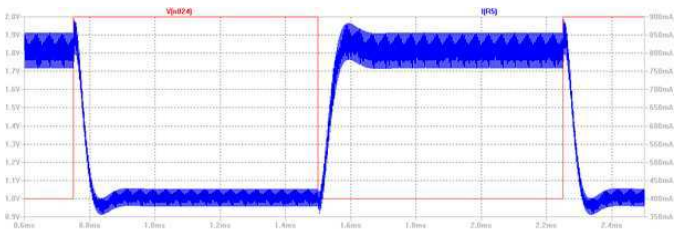

Fig. 12. Simulation result (with LTSpice) for the LED considered to buil the transfer function, $V_{0}=18 \mathrm{~V}$ and $R_{L}=1 \Omega$.

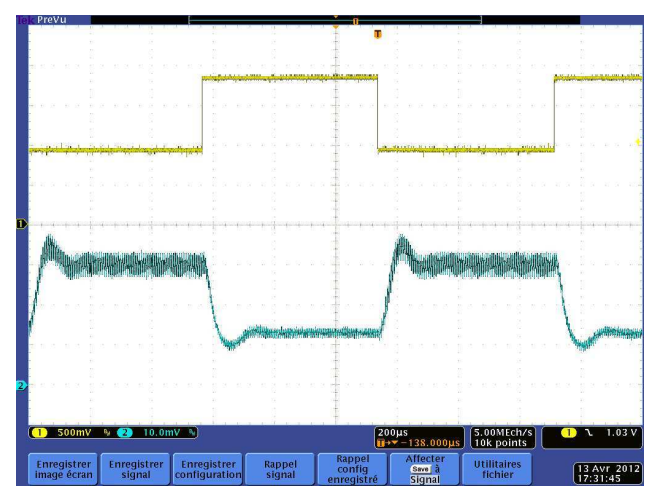

Fig. 13. Experimental result for the LED considered to build the transfer function, $V_{0}=18 \mathrm{~V}$ and $R_{L}=1 \Omega$.

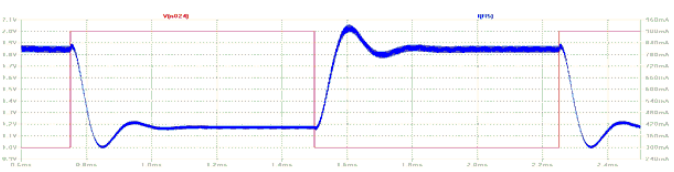

Fig. 14. Simulation result for another LED with $V_{0}=11 V$ and $R_{L}=3 \Omega$.

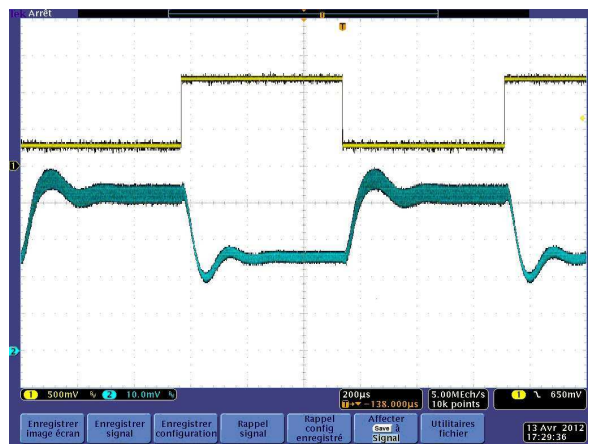

Fig. 15. Experimental result for another LED with $V_{0}=11 \mathrm{~V}$ and $R_{L}=3 \Omega$.

[14] John Betten, Benefits of a coupled-inductor SEPIC converter, [Online]. Available: http://www.ti.com/lit/an/slyt411/slyt411.pdf

[15] A. Jaafar, P. Lefranc, E. Godoy, X. Lin-Shi, A. Fayaz, and N. Li, Experimental validation with a control point of view analysis of the SEPIC converter, IEEE Industrial Electronics Society Conference, Porto, pp. 467-472, 2009.

[16] Ray Ridley, Analyzing the Sepic Converter, [Online]. Available: http://www.switchingpowermagazine.com/downloads/ Sepic\%20Analysis.pdf 